\title{
Remdesivir: a eficácia da nova droga no controle do coronavírus da síndrome respiratória aguda grave 2 (sars-cov-2) recentemente emergido
}

\author{
Remdesivir: the efficacy of novel drug to control the recently emerged noval severe acute \\ respiratory syndrome coronavirus 2 (sars-cov-2)
}
Remdesivir: la eficacia del nuevo fármaco para control del coronavirus del síndrome respiratorio agudo severo (sars-cov-2) recientemente emergido

Diego Lisboa Rios ${ }^{1 *}$, Thiago Araújo Andrade ${ }^{1}$, Silvia de Siqueira Costa², Paula Margarita Salazar Torres $^{3}$, Lucas Roberto da Silva ${ }^{3}$, Pedro Gontijo Carneiro ${ }^{1}$, Kerley dos Santos Alves ${ }^{4}$, Welington Ribeiro Aquino Marques ${ }^{4}$, João Batista Matos Júnior ${ }^{5}$, Fabyola Antunes Gonçalves Souza ${ }^{4}$.

\section{RESUMO}

Objetivo: O objetivo do presente estudo foi realizar uma revisão sistemática sobre o efeito do medicamento Remdesivir no tratamento da COVID-19. Métodos: Foi realizada pesquisa no Pubmed e em outras plataformas de buscas pelos seguintes termos: "COVID-19" ou "SARS-CoV-2", "remdesivir" e "revisão sistemática". Resultados: Por meio da seleção de 8 artigos para inclusão nesta revisão sistemática, sendo dois deles estudos clínicos de Fase III, randomizados, duplo-cegos e controlados por placebo. Com todas as etapas concluídas, encontraram eficácia de Remdesivir. Entre os dois estudos in vitro, um deles, mostrou que o medicamento possui eficácia na inibição da infecção pelo vírus, enquanto outro complementou mostrando que essa inibição ocorre justamente pela via da qual o Remdesivir é bem conhecido. Por fim, foi identificado o tratamento bem-sucedido com Remdesivir no primeiro caso de COVID-19 nos Estados Unidos. Considerações Finais: A partir dessa revisão sistemática, o uso de Remdesivir é considerado promissor no tratamento da COVID-19. Todavia, outros estudos clínicos precisam ser realizados para comprovar sua eficácia e segurança.

Palavras-chave: COVID-19, Coronavírus da síndrome respiratória águda grave 2, Antiviral, Fármaco.

\begin{abstract}
Objective: The aim of the present study was to conduct a systematic review of the effect of the drug Remdesivir in the treatment of COVID-19. Methods: Research was carried out on Pubmed and other search platforms using the following terms: "COVID-19" or "SARS-CoV-2", "remdesivir" and "systematic review". Results: Through the selection of 8 articles for inclusion in this systematic review, two of which were phase III clinical studies, randomized, double-blind and placebo-controlled. With all stages completed, they found Remdesivir effective. Between the two in vitro studies, one showed that the drug is effective in inhibiting the infection by the virus, while another complemented it by showing that this inhibition occurs precisely through the path for which Remdesivir is well known. Finally, successful treatment with Remdesivir was identified in the first case of COVID-19 in the United States. Final Considerations: Based on this systematic review, the use of Remdesivir is considered promising in the treatment of COVID-19. However, other clinical studies need to be carried out to prove its effectiveness and safety.
\end{abstract}

Keywords: COVID-19, Severe acute respiratory syndrome coronavirus 2, Antiviral, Drug.

\footnotetext{
1 Universidade Federal de Minas Gerais (UFMG), Belo Horizonte - MG. *E-mail: lisboa.zootec@gmail.com

2 Universidade José do Rosário Vellano (UNIFENAS), Divinópolis - MG.

3 Universidade Federal de São João del-Rei (UFSJ), Divinópolis - MG.

4 Universidade Federal de Ouro Preto (UFOP), Ouro Preto - MG.

5 Instituto Federal do Acre (IFAC), Rio Branco - AC.
} 


\section{RESUMEN}

Objetivo: El objetivo del presente estudio fue realizar una revisión sistemática del efecto del fármaco Remdesivir en el tratamiento de COVID-19. Métodos: La investigación se llevó a cabo en Pubmed y otras plataformas de búsqueda utilizando los siguientes términos: "COVID-19" o "SARS-CoV-2", "remdesivir" y "revisión sistemática". Resultados: Mediante la selección de 8 artículos para su inclusión en esta revisión sistemática, dos de los cuales fueron estudios clínicos Fase III, aleatorizados, doble ciego y controlados con placebo. Con todas las etapas completadas, encontraron que Remdesivir era efectivo. Entre los dos estudios in vitro, uno demostró que el fármaco es eficaz para inhibir la infección por el virus, mientras que otro lo complementó al mostrar que esta inhibición se produce precisamente por la vía por la que Remdesivir es bien conocido. Finalmente, se identificó un tratamiento exitoso con Remdesivir en el primer caso de COVID-19 en los Estados Unidos. Consideraciones Finales: Según esta revisión sistemática, el uso de Remdesivir se considera prometedor en el tratamiento de COVID-19. Sin embargo, es necesario realizar otros estudios clínicos para demostrar su eficacia y seguridad.

Palabras clave: COVID-19, Síndrome respiratorio agudo severo coronavirus 2, Antiviral, Medicamento.

\section{INTRODUÇÃO}

A explosão do novo Coronavírus 2019, oficialmente conhecido como Coronavírus da Síndrome Respiratória Aguda Grave 2 (SARS-CoV-2), emergiu como uma crise de saúde mundial e, logo a Organização de Saúde Mundial (OMS) decretou pandemia (TU H, et al., 2020). A doença pelo Coronavírus 2019 (COVID19) é uma síndrome respiratória causada por uma nova infecção por SARS-CoV-2. O novo SARS-CoV-2 pertence à família dos Coronavírus, gênero dos BetaCoronavírus e foi descoberto pela primeira vez no mês de dezembro de 2019 na cidade de Wuhan, província de Hubei, na China. Os Coronavírus são vírus de RNA fita simples (ssRNA) de sentido positivo, com tamanho genômico de 29,9 kb (WANG Y, et al., 2020). O novo SARS-CoV-2 possui alta semelhança filogenética com o Coronavírus da Síndrome Respiratória Aguda Grave (SARS-CoV) e com o Coronavírus da Síndrome Respiratória do Oriente Médio (MERS-CoV) (CHAN JF, et al., 2020). Entretanto, SARS-CoV-2 possui de 10 a 20 vezes mais afinidade com o seu alvo nas células hospedeiras humanas, além de se replicar 3 vezes mais que o SARS-CoV (WRAPP D, et al., 2020).

Medidas de contenção em todo o mundo foram tomadas para combater o surto de COVID-19, no entanto o vírus atingiu rapidamente todo o mundo e os casos aumentam constantemente. Até 6 de novembro de 2020, foram registrados 48.534 .508 casos confirmados e 1.231 .017 mortes em todo o mundo (WHO, 2020). Os sintomas mais comuns entre pacientes acometidos com a COVID-19 são febre, náusea, fadiga, tosse seca, diarreia ou outro tipo de distúrbios gastrointestinais. A doença tem sintomas mais brandos em comparação ao SARS-CoV e MERS-CoV, no entanto o SARS-CoV-2 se dissemina com maior rapidez (KWONG KC, et al., 2020).

O processo de infecção do SARS-CoV-2 já é bem conhecido e tem fornecido importantes informações, tanto sobre a progressão da infecção, quanto sobre a resposta do sistema imune e o desenvolvimento de estratégias para possíveis terapias antivirais. A infecção se inicia com a interação do domínio de ligação do receptor (RBD) da proteína Spike da superfície do vírus ao receptor da enzima conversora de angiotensina 2 (ACE2) da superfície celular. Assim, ocorre a fusão da membrana viral com a célula hospedeira e a liberação do genoma viral para o citoplasma, que posteriormente é transcrito e traduzido em proteínas não estruturais utilizando a maquinaria da célula hospedeira. As proteínas não estruturais formam um complexo de replicação e transcrição chamado de complexo RNA replicase-transcriptase que geram fitas de RNA negativas a partir do molde de RNA sentido positivo. Esta nova fita será posteriormente traduzida em proteínas estruturais do vírus (FENG W, et al., 2020)

Após todo esse processo, no citoplasma da célula infectada, glicoproteínas estruturais virais recémmontadas são inseridas nas membranas de tráfego intracelular localizadas entre o retículo endoplasmático e o Complexo de Golgi, que se combinam com o RNA genômico para a montagem de novos vírus. As vesículas contendo essas partículas são liberadas por exocitose para infectar as células vizinhas. Cada uma das células infectadas tem capacidade de produzir milhares de novas partículas virais, que podem se espalhar para os brônquios e atingir os alvéolos, podendo causar pneumonias, outras infecções respiratórias ou, em casos 
mais graves, insuficiência respiratória e morte (FENG W, et al., 2020; HUANG J, et al., 2020; TAY MZ, et al., 2020).

Pesquisas estão em andamento para descobrir drogas de ação rápida para a COVID-19. Muitos estudos investigam medicamentos reutilizáveis usados na terapia de doenças com sintomas semelhantes. No entanto, até o momento nenhum medicamento eficaz que controle a doença foi disponibilizado. Portanto, a busca contínua por vacinas e medicamentos é crucial para combater a pandemia. Atualmente, diversos ensaios clínicos vêm sendo realizados a fim de avaliar diferentes opções terapêuticas.

Medicamentos incluindo Hidroxicloroquina, Remdesivir, Cloroquina, Ritonavir, Lopinavi, Arbidol e Interferon estão em ensaios clínicos randomizados (RCTs) para a avaliação de sua segurança e eficácia em pacientes com COVID-19 (HUANG C, et al., 2020; GHOST AK, 2020). O Remdesivir (GS-5734) é um prófármaco de fosforamidato análogo de nucleotídeo antiviral desenvolvido pela empresa farmacêutica americana "Gilead Sciences". Tal composto foi usado no tratamento de infecções pelo vírus Ebola durante o surto na África. O Remdesivir está entre as drogas em investigação que mostra efeito promissor contra a COVID-19, possivelmente devido à sua ação antiviral de amplo espectro, incluindo alguns vírus de RNA (BEISEL JH, et al., 2020; CAO YC, et al., 2020).

O pró-fármaco Remdesivir é um análogo do nucleotídeo adenosina substituído (ATP) 1-ciano e é metabolizado em células-alvo em um trifosfato de nucleosídeo ativo (RDV-TP) semelhante ao ATP que inibe as enzimas RNA polimerases dependentes de RNA viral (RdRp), limitando a produção de RNA viral no estágio inicial da infecção (AGOSTINI ML, et al., 2020; BARLOW A, et al., 2020). Outros possíveis mecanismos de ação do Remdesivir podem ser a mutagênese e a terminação da cadeia da transcrição do RNA. Sendo que também foi descoberto, a partir de um estudo in vitro, que o amálgama de Remdesivir nos estágios iniciais de replicação do vírus teve ação mais eficaz dependente do tempo (Figura 1) (BARLOW A, et al., 2020).

Figura 1 - Mecanismo de ação do Remdesivir.
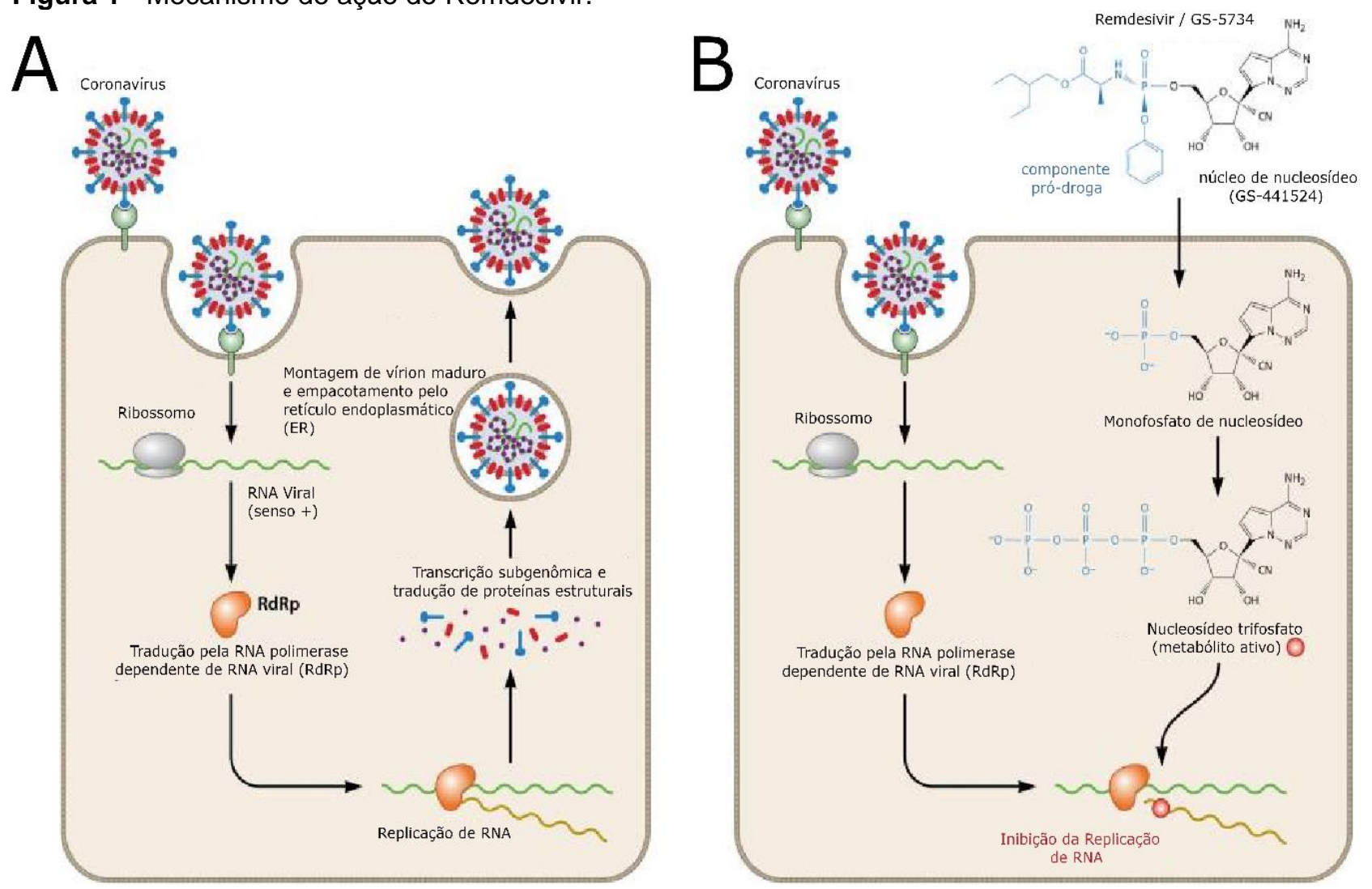

Legenda: Ativação intracelular do Remdesivir (GS-5734) e inibição da replicação do Coronavírus. A) Célula hospedeira sem o Remdesivir. B) A passagem através da membrana celular pelo Remdesivir é facilitada pelo componente pró-fármaco ligado ao núcleo do nucleosídeo. Ao entrar na célula alvo, o pronucleotídeo passa por outras etapas de fosforilação para se tornar o metabólito trifosfato ativo, que efetivamente inibe a replicação do RNA viral. O retardo da terminação da cadeia é causado pelos seguintes processos: (I) má 
integração do nucleosídeo trifosfato (NTP) em replicação do RNA por RdRp, (II) prevenção de maior alongamento da cadeia após NTP mais 3 nucleosídeos adicionais e (III) término prematuro da síntese de RNA. Fonte: Rios DL, et al., 2020.

Pesquisas clínicas geralmente são classificadas em 4 fases. Quando se analisa clinicamente um fármaco, este deve ter sido aprovado em testes pré-clínicos, ou seja, aspectos de segurança são avaliados em experimentos com animais modelo antes da aplicação do fármaco em seres humanos.

A Fase I refere-se ao uso do medicamento pela primeira vez em seres humanos, geralmente em indivíduos saudáveis e que não possuem a doença para qual o medicamento está sendo estudado, com objetivo de testar a segurança.

Na Fase II são necessários cerca de 100 a 300 indivíduos que já apresentam a doença ou condição para a qual o fármaco está sendo estudado, cujo objetivo é obter mais dados acerca da segurança em pacientes acometidos pela doença, além de dar início a avaliação da eficácia do novo fármaco.

Depois de concluído o estudo piloto, inicia-se na Fase III grandes experimentos e estudos multicêntricos, no qual milhares de pacientes são acompanhados, em média de 5 à 10 mil, em um período maior de tempo, usualmente sendo comparados a outros fármacos já existentes e recomendados para o problema em questão. O objetivo dos testes é fornecer todas as informações necessárias para a elaboração das especificações contidas no rótulo e na bula do medicamento. Para aprovação e registro do novo fármaco, esses resultados de Fase III serão avaliados pelos órgãos competentes e assim começar a Fase IV.

Após a admissão pelas agências sanitárias, logo o fármaco é disponibilizado no mercado onde são realizados monitoramentos constantes sobre o pela população. Nessa etapa, denominada de Fase IV ou Farmacovigilância, o objetivo é definir efeitos possíveis efeitos adversos não relatados ou inconclusivos, bem como fatores de riscos, e assim depreender sobre a segurança e eficácia do medicamento (WHO, 2020)

Contudo, a urgência na saúde pública, na situação atual e na complexidade dos processos de pesquisa e acesso à uma população de um medicamento, ressalta-se a importância de análises de potenciais e eficácias de drogas promissoras contra COVID-19. Dado o exposto, o objetivo do presente estudo foi avaliar o efeito do Remdesivir em pacientes com COVID-19 por meio de uma revisão sistemática.

\section{MÉTODOS}

Realizamos uma revisão sistemática usando bancos de dados online como PUBMED (busca de livre acesso à base de dados MEDLINE), Embase (banco de dados bibliográfico biomédico e farmacológico da literatura publicada), Clinicaltrials.gov, ScienceDirect e Google Scholar. As pesquisas incluíram combinações de termos MeSH (Medical Subject Headings) que descrevem "COVID-19", "tratamento", como "SARS- cov2", "agentes antivirais", "Remdesivir", "análogo de nucleotídeo", "controlado randomizado ensaios" e "GS5734". Os dados foram coletados a partir de estudos realizados durante os anos de 2019 a 2020 (Figura 2).

Os critérios de inclusão deste estudo foram os seguintes: (a) A população do estudo inclui pacientes COVID-19 confirmado; (b) A população do estudo inclui pacientes de ambos os gêneros; (c) Em qualquer estágio clínico da doença, portanto, caso leve, moderado ou grave / crítico; (d) Uso de Remdesivir em qualquer dose; (e) Artigos originais e de revisão foram publicados em revistas revisadas por pares.

Os artigos de pesquisa selecionados e incluídos no presente estudo foram avaliados criticamente para avaliar a validade da pesquisa em relação à erros e limitações para reduzir possíveis vieses de acordo com as seguintes questões: (a) Quais são os objetivos da pesquisa e o desenho do estudo evidentemente declarados?; (b) A pesquisa é original?; (c) Os artigos de pesquisa apresentam novas descobertas?; (d) A questão da pesquisa cobre o grupo ou população de pacientes, intervenção ou terapia e a importância do resultado da pesquisa?; (e) Os pesquisadores usam metodologia e relatórios adequados?; (f) A hipótese do estudo foi devidamente abordada?; (g) Os dados e análises são precisos e os autores tiram as conclusões apropriadas com base nos resultados?; (h) O resultado do estudo é útil para a prática clínica?; (i) O risco de um diagnóstico ou tratamento prevalece sobre os benefícios potenciais?; (j) A análise dos dados é precisa?; (k) Quais níveis de incerteza envolvem quaisquer resultados? 
Como limitações, podem-se incluir: (a) pesquisas online apenas por artigos escritos em inglês (não incluímos artigos escritos em outros idiomas); (b) procura por artigos apenas nas plataformas de busca, PUBMED, Clinicaltrials.gov, Science Direct e Google Scholar.

Figura 2 - Diagrama do fluxo de revisão sistemática.

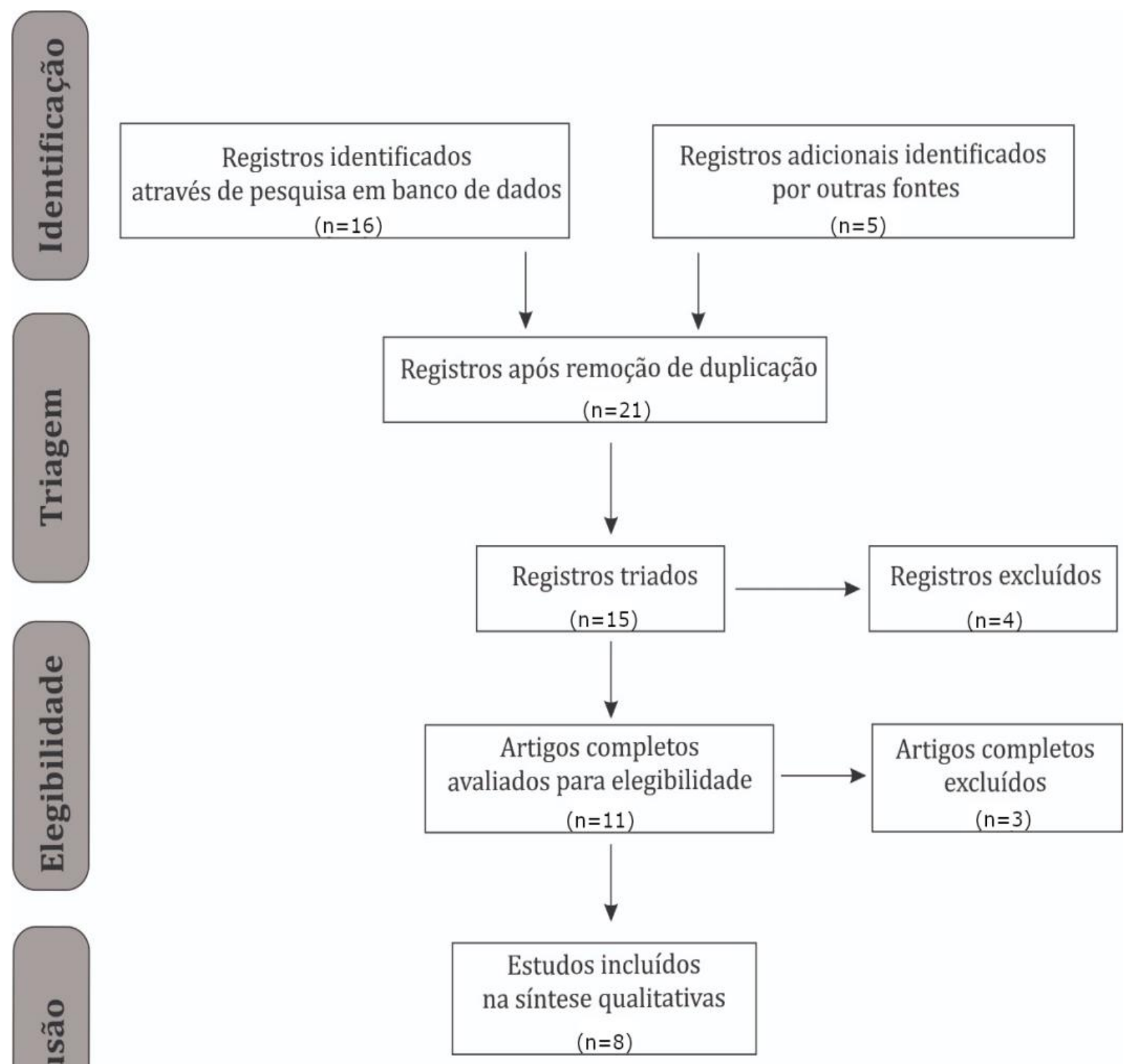

Legenda: Workflow metodológico da busca, análise e curadoria dos trabalhos relacionados a COVID-19 e Remdesivir. A cada etapa, foram selecionados apenas os trabalhos que cumpriam os requisitos necessários para passar para a próxima etapa.

Fonte: Rios DL, et al., 2020.

RESULTADOS E DISCUSSÃO 
Atualmente, há vários casos de uso do Remdesivir relacionados ao sucesso no tratamento da COVID-19. The New England Journal of Medicine relatou todo o curso de recuperação do primeiro paciente com COVID19 nos Estados Unidos. O paciente visitou Wuhan, mas não foi exposto diretamente ao mercado Wuhan Seafood Market (hipótese principal do marco zero da doença), nem teve contato direto com os pacientes diagnosticados. Ele retornou a Washington em 15 de janeiro de 2020.

Em 19 de janeiro, devido a tosse e febre por quatro dias, foi ao hospital para tratamento de emergência, sendo então diagnosticado com COVID-19. Sua condição permaneceu estável do segundo ao quinto dia de internação (do sexto ao nono dia do início dos sintomas). Na noite do quinto dia de internação, a saturação de oxigênio no sangue diminuiu para $90 \%$. O quadro continuou a piorar e as radiografias de tórax no sexto dia da internação mostraram características típicas de COVID-19.

Com o agravamento contínuo dos sintomas clínicos do paciente, os médicos responsáveis iniciaram o tratamento com Remdesivir na noite do 6으 dia de internação e começaram a aplicar o fármaco por via intravenosa na noite do sétimo dia. Não foram apresentadas reações adversas. No oitavo dia de internação, os sintomas clínicos do paciente melhoraram e a saturação de oxigênio aumentou para $94 \%$. Embora o paciente ainda estivesse hospitalizado em 30 de janeiro de 2020, este estava assintomático, exceto por leve tosse e corrimento nasal ocasional (KIM J, et al., 2020).

É importante notar que a partir dos dados de KIM J, et al. (2020), foi verificado que a carga viral do paciente diminuiu antes da injeção de Remdesivir, o que não é descrito em detalhes no relatório original (Quadro 1). Sabe-se que a infecção viral é autolimitada, e o paciente em questão é um caso de infecção de leve a moderado, com febre controlada.

Portanto, é possível que sua recuperação esteja relacionada aos mecanismos de autodefesa inatos e o tratamento tenha dado apenas suporte. Não se pode inferir com precisão que a melhora do estado do paciente após a ingestão do medicamento esteja definitivamente ligada ao tratamento com Remdesivir.

Os sintomas clínicos, principalmente respiratórios, melhoraram significativamente em 24 horas, trazendo potencial benefício para o tratamento de pacientes com COVID-19 grave. Para COVID-19, nenhum medicamento específico está disponível até o momento e espera-se que o Remdesivir seja um "medicamento específico". Para as doenças infecciosas agudas, reduzir o número de cópias virais no corpo é o ponto chave, além disso, a eficácia do medicamento deve ser focada nos dados de farmacocinética e cinética de COVID19, em estudos clínicos de Fase III em andamento (KIM J, et al., 2020).

Quadro 1 - Carga viral no primeiro caso de recuperação de paciente com COVID-19 nos Estados Unidos.

\begin{tabular}{|c|c|c|c|}
\hline & $\begin{array}{c}\mathbf{4}^{\circ} \text { dia do início dos } \\
\text { sintomas }\end{array}$ & $\begin{array}{c}7^{\circ} \text { dia do início dos } \\
\text { sintomas }\end{array}$ & $\begin{array}{c}\mathbf{1 1}^{\circ} \text { dia do início dos } \\
\text { sintomas }\end{array}$ \\
\hline $\begin{array}{c}\text { Cotonete } \\
\text { nasofaríngeo }\end{array}$ & $\mathrm{Ct}^{\star}, 18-20$ & $\mathrm{Ct}, 23-24$ & $\mathrm{Ct}, 33-34$ \\
\hline $\begin{array}{c}\text { Cotonete } \\
\text { orofaríngeo }\end{array}$ & $\mathrm{Ct}, 21-22$ & $\mathrm{Ct}, 32-33$ & $\mathrm{Ct}, 36-40$ \\
\hline
\end{tabular}

Legenda: *Ct mais alto significa carga viral mais baixa.

Fonte: Rios DL, et al., 2020. Baseado em Wang Y, et al., 2020. 
Apesar de haver vários casos de sucesso no tratamento da COVID-19 com o Remdesivir, até o momento existem poucos estudos clínicos referentes ao efeito do fármaco no tratamento da doença. Neste trabalho foram selecionados 16 estudos após busca online, porém apenas 8 estudos foram considerados elegíveis para o estudo do uso de Remdesivir no tratamento de COVID-19, por serem estudos que cumpriram com os pré-requisitos metodológicos. Os dados existentes sobre o uso de Remdesivir estão disponíveis principalmente em cultura de células humanas in vitro, estudos in vivo em camundongos e primatas não humanos (Quadro 2). 


\section{Revista Eletrônica Acervo Saúde / Electronic Journal Collection Health | ISSN 2178-2091}

Quadro 2 - Características dos estudos que relacionaram o efeito de Remdesivir na COVID-19.

\begin{tabular}{|c|c|c|c|}
\hline Autor & $\begin{array}{c}\text { Amostras } \\
\text { Tamanho / linha celular }\end{array}$ & Tipo de estudo & Resultados \\
\hline $\begin{array}{l}\text { BEIGEL JH, et al., } \\
2020\end{array}$ & 538 & $\begin{array}{l}\text { Ensaio hospitalar, randomizado, } \\
\text { controlado por placebo e } \\
\text { Remdesivir intravenoso. }\end{array}$ & $\begin{array}{l}\text { Avaliaram o tratamento da COVID-19 com Remdesivir em } \\
\text { comparação com o placebo. A partir da observação inicial, eles } \\
\text { descobriram que o Remdesivir foi melhor do que o placebo na redução } \\
\text { do tempo de recuperação em pacientes adultos hospitalizados com } \\
\text { COVID-19 e o estudo também confirmou a menor infecção do trato } \\
\text { respiratório devido ao tratamento com Remdesivir }\end{array}$ \\
\hline WANG Y, et al., 2020 & 158 & $\begin{array}{l}\text { Ensaio multicêntrico } \\
\text { randomizado, duplo-cego, } \\
\text { controlado por placebo. }\end{array}$ & $\begin{array}{l}\text { Foi observado que, no caso de pacientes adultos com COVID-19, o } \\
\text { tratamento com Remdesivir não estava significativamente associado } \\
\text { à benefícios clínicos. No entanto, o estudo também evidenciou } \\
\text { redução no tempo para melhora clínica naqueles tratados } \\
\text { anteriormente com Remdesivir. }\end{array}$ \\
\hline WANG M, et al., 2020 & $\begin{array}{l}\text { Linhagem de células } \\
\text { Huh7 de câncer de fígado } \\
\text { humano. }\end{array}$ & In vitro & $\begin{array}{l}\text { Remdesivir inibiu a infecção pelo vírus da COVID-19 de forma } \\
\text { eficiente na linha celular humana (Huh-7), que é sensível ao SARS- } \\
\text { CoV-2. }\end{array}$ \\
\hline $\begin{array}{c}\text { KUJAWSKI SA, et al., } \\
2020\end{array}$ & 3 & $\begin{array}{l}\text { Ensaio de Remdesivir } \\
\text { intravenoso. }\end{array}$ & $\begin{array}{l}\text { Uma vez que o medicamento Remdesivir não foi administrado como } \\
\text { parte de um ensaio clínico randomizado (RCT), o estudo foi incapaz } \\
\text { de avaliar a eficácia ou segurança do Remdesivir }\end{array}$ \\
\hline $\begin{array}{l}\text { GORDON CJ, et al., } \\
2020\end{array}$ & Células de inseto (Sf9). & In Vitro & $\begin{array}{l}\text { O estudo forneceu evidências da ação especifica ao alvo do } \\
\text { Remdesivir, uma vez que o RDV-TP foi integrado de forma menos } \\
\text { eficiente pelo vírus Lassa relacionado à distância, RdRp, enquanto a } \\
\text { terminação da síntese de RNA não foi encontrada. O estudo fornece } \\
\text { um novo mecanismo unificador desenvolvido de inibição da síntese de } \\
\text { RNA mediada por RDV no SARS-CoV-2 e identifica o Remdesivir } \\
\text { como um antiviral de ação direta. }\end{array}$ \\
\hline CAO YC, et al., 2020 & - & Revisão & $\begin{array}{l}\text { O estudo demonstrou estrutura, imunogenicidade e patogênese do } \\
\text { SARS-CoV-2. Além disso, eles analisaram as ações farmacológicas } \\
\text { do Remdesivir para reconhecer a viabilidade de conduzir pesquisas } \\
\text { com Remdesivir e COVID-19. }\end{array}$ \\
\hline HUANG C, et al., 2020 & - & Revisão & $\begin{array}{l}\text { Discutiu o desenvolvimento de inibidores de RNA polimerases } \\
\text { dependentes de RNA (RdRp) eficazes e prósperos. }\end{array}$ \\
\hline $\begin{array}{l}\text { BARLOW A, et al., } \\
2020\end{array}$ & - & Revisão & É discutido o modo de ação e efeitos colaterais do Remdesivir \\
\hline
\end{tabular}

Fonte: Rios DL, et al., 2020.

REAS/EJCH | Vol.13(1) | e5877 | DOI: https://doi.org/10.25248/reas.e5877.2021 Página 8 de 11 
Dos 8 estudos elegíveis, apenas 2 eram ensaios clínicos randomizados controlados com placebo e com administração de Remdesivir intravenosa; 2 estudos in vitro sobre Remdesivir e COVID-19; 3 revisões de artigos relevantes e apenas um ensaio de Remdesivir intravenoso não considerado ensaio controlado randomizado durante o estudo. Para considerações práticas do tratamento antiviral com Remdesivir contra COVID-19, foi proposto padrão conforme o Quadro 3.

Quadro 3 - Considerações práticas do tratamento antiviral com Remdesivir proposto contra COVID-19.

\begin{tabular}{|c|c|c|c|c|}
\hline Natureza & Dose & Administração & Interação do Fármaco & $\begin{array}{c}\text { Efeitos } \\
\text { colaterais }\end{array}$ \\
\hline $\begin{array}{c}\text { Análogo de } \\
\text { nucleotídeo } \\
\text { (GS-5734), } \\
\text { contém } \beta- \\
\text { ciclodextrina, } \\
\text { C27H35N6O8 } \\
\text { P (fórmula } \\
\text { molecular), } \\
\text { 602,6g / mol } \\
\text { (peso } \\
\text { molecular) }\end{array}$ & $\begin{array}{l}200 \text { mg por via } \\
\text { intravenosa } \\
\text { seguida de } 100 \\
\text { mg / dia por via } \\
\text { intravenosa por } \\
5-10 \text { dias } \\
\text { (ClinicalTrials, } \\
\text { 2020) }\end{array}$ & 30 minutos & $\begin{array}{l}\text { Remdesivir é metabolizado } \\
\text { ativo, um nucleosídeo } \\
\text { trifosforilado, via quinase } \\
\text { intracelular anabólica e } \\
\text { termina a produção de } \\
\text { RNA viral nas fases iniciais } \\
\text { da infecção. }\end{array}$ & $\begin{array}{c}\text { Vômito, náusea, } \\
\text { gastroparesia } \\
\text { ou sangramento } \\
\text { retal }\end{array}$ \\
\hline
\end{tabular}

Fonte: Rios DL, et al., 2020 adaptado de Beigel JH, et al., 2020.

Wang M, et al. (2020) conduziram um estudo in vitro sobre Remdesivir e descobriram que este possui eficácia em inibir a replicação do SARS-CoV-2, sendo que conduziram o estudo usando células humanas Huh7. Embora na Fase II o Remdesivir não tenha sido tão eficiente quanto outros medicamentos concorrentes, este mostrou boa segurança e farmacocinétical. Os ensaios clínicos de Fase III do Remdesivir em pacientes com COVID-19 estão em andamento. Espera-se que o resultado do estudo de Fase III façam com que o Remdesivir volte como medicamento antiviral comprovado (TAY MZ, et al., 2020).

Wang Y, et al. (2020) publicaram o primeiro ensaio clínico randomizado, duplo-cego, controlado por placebo avaliando o efeito do Remdesivir intravenoso entre adultos hospitalizados positivos para COVID-19. Estes relataram que nos pacientes tratados, a diferença do avanço clínico da doença não foi significativa entre os grupos tratados com Remdesivir; no entanto, foi observada melhora clínica no grupo tratado com Remdesivir em comparação com o grupo controle, principalmente nos pacientes tratados dentro de 10 dias do início dos sintomas. Para o estudo, foi interpretado que, no caso de pacientes adultos com COVID-19, o tratamento com Remdesivir não estava significativamente associado à benefícios clínicos. Contudo, o estudo também evidenciou redução no tempo para melhora clínica naqueles tratados anteriormente com Remdesivir.

Beigel ML, et al. (2020) conduziram uma série de ensaios de Fase III, randomizados, duplo-cegos e controlados por placebo para avaliar a eficácia clínica e a segurança de Remdesivir em adultos internados em hospital com COVID-19. Nesse estudo, eles avaliaram o tratamento de COVID-19 com Remdesivir em comparação com placebo. A partir da observação inicial, eles descobriram que o Remdesivir foi melhor do que o placebo na redução do tempo de recuperação dos pacientes. Além disto, foi confirmada uma menor infecção do trato respiratório devido ao tratamento com Remdesivir. Entretanto, este trabalho requer confirmação em estudos populacionais maiores (AGOSTINI JH, et al., 2018).

Remdesivir é ativo in vitro contra vários Coronavírus (CoVs), incluindo SARS-CoV-2, e seu mecanismo de ação foi estudado extensivamente (WANG M, et al., 2020; OGANDO NS, et al., 2020; CHOY KT, et al., 2020; US FOOD AND DRUG ADMINISTRATION, 2020). Estudos em animais que incluíram modelos de primatas não humanos de MERS-CoV e, recentemente, SARS-CoV-2 apoiam sua eficácia, especialmente quando administrado no início da doença (de WIT E, et al., 2020; WILLIAMSON BN, et al., 2020). Finalmente, um ensaio de Fase III mostrou efeitos clínicos benéficos do Remdesivir em pacientes que requerem oxigênio suplementar, enquanto a eficácia clínica para pacientes criticamente enfermos que requerem ventilação mecânica não pôde ser demonstrada (BEIGEL JH, et al., 2020). Remdesivir reduz o tempo de recuperação em $31 \%$, o que é um efeito relativamente modesto, mas claramente terapêutico (BEIGEL JH, et al., 2020). 
Além desses efeitos benéficos para os pacientes, o tratamento pode ajudar a reduzir o número de dias de internação, com efeitos positivos sobre os custos e problemas de capacidade hospitalares que surgiram durante a pandemia de COVID-19 em vários países. No que diz respeito à mortalidade, uma menor taxa de mortalidade em 14 dias de pacientes tratados com Remdesivir foi relatada no estudo ACTT (Adaptive Covid19 Treatment Trial), o que pode indicar um efeito benéfico, mas não estatisticamente significativo (BEIGEL $\mathrm{JH}$, et al., 2020). Levando em consideração que o estudo não possuía capacidade para avaliar a mortalidade, este ainda é um sinal positivo que deve ser avaliado em estudos de grande porte.

Em estudo com meta-análise de dados agrupados, dois ensaios clínicos randomizados controlados disponíveis, e que ainda estão em revisão por pares, conclui uma redução estatisticamente significativa na mortalidade (Razão de Risco (RR), 0,69; $95 \%$ de Intervalo de Confiança (IC), 0,49 a 0,99) (ALEXANDER PE, et al., 2020).

Embora os dados clínicos sobre o Remdesivir ainda não tenham sido totalmente publicados, as autorizações de emergência e a aprovação recente da EMA são encorajadoras, visto que a maioria dos outros medicamentos em investigação falhou até agora, deixando o Remdesivir como o único antiviral com eficácia clinicamente comprovada contra COVID -19 até o momento. Os resultados completos do estudo ACTT, incluindo os impactos nas cargas virais e na mortalidade no dia 28 , bem como os resultados dos ensaios e meta-análises em andamento, fornecerão mais informações sobre a eficácia clínica do Remdesivir (CAO B, et al., 2020; BORBA MGS, et al., 2020).

A eficácia terapêutica do Remdesivir pode ainda ser melhorada pela adição de outros antivirais ou agentes imunomoduladores. Recentemente, foi demonstrado que os glicocorticóides são capazes de melhorar os resultados clínicos em casos de COVID-19 grave e crítico (RECOVERY, 2020). Com base nesses dados, pode-se esperar que os médicos usem Remdesivir e glicocorticoides para tratar pacientes com COVID-19 em estado grave ou crítico. No entanto, a terapia combinada deve ser usada com cautela, pois podem ocorrer interações medicamentosas.

In vitro, o Remdesivir atua como substrato ou inibidor de várias enzimas metabolizadoras de medicamentos (por exemplo, CYP3A4), o que pode influenciar os níveis de exposição de outros agentes terapêuticos. Além disso, esses agentes podem interferir na farmacocinética do Remdesivir. A droga imunomoduladora hidroxicloroquina, por exemplo, parece reduzir a atividade antiviral do Remdesivir ao prejudicar sua ativação metabólica intracelular. Outra abordagem que pode melhorar os resultados clínicos poderia ser a terapia combinada com drogas antivirais diretas que visam vários processos dentro do ciclo de vida viral. Embora essa estratégia seja altamente eficaz na terapia de infecções crônicas com HIV e HCV, não está claro se isso é verdade para infecções agudas com SARS-CoV-2. Os ensaios clínicos avaliando a terapia combinada são necessários para estimar seu papel no COVID-19 (US FOOD AND DRUG ADMINISTRATION, 2020).

\section{CONSIDERAÇÕES FINAIS}

Remdesivir é um inibidor da replicação de RNA viral e foi efetivamente usado contra vírus de RNA como o SARS-CoV e o MERS-CoV. Recentemente o fármaco foi testado contra infecções por SARS-Cov-2, inicialmente em células in vitro e não humanas. O Remdesivir apresentou resultados terapêuticos promissores para o controle do COVID-19. Apesar dos dados de eficácia do medicamento em pacientes positivos para COVID-19 nos ensaios clínicos de Fase III ainda serem escassos, recentemente, foram relatados resultados de dois estudos de Fase III randomizados, duplo-cegos e controlados por placebo em hospitais. Ambos os estudos mostraram eficácia de Remdesivir em pacientes positivos para COVID-19. No entanto, verificaram que o tratamento com Remdesivir não foi significativamente associado à benefícios clínicos. Em conclusão, esta é a primeira revisão sistemática sobre o efeito do Remdesivir no tratamento do COVID-19, sendo que a partir desta, sugerimos que é promissor o uso do Remdesivir para tratar pacientes positivos, potencializando seu efeito quando combinado com outros fármacos, como os glicocorticóides. Por fim, é necessário que futuros estudos clínicos, com maior número de pacientes, sejam considerados para atestar a eficácia e segurança do Remdesivir no tratamento da COVID-19. 


\section{REFERÊNCIAS}

1. AGOSTINI ML, et al. Coronavirus susceptibility to the antiviral remdesivir (GS-5734) is mediated by the viral polymerase and the proofreading exoribonuclease. mBio, 2018; 9(2): 00221-18.

2. ALEXANDER PE, et al. Remdesivir use in patients with coronavirus COVID-19 disease: a systematic review and meta-analysis. medRxiv, 2020; 2020.05.23.20110932.

3. BARLOW A, et al. Review of emerging pharmacotherapy for the treatment of coronavirus disease 2019. Pharmacotherapy, 2020; 40(5): 416-437.

4. BEIGEL JH, et al. Remdesivir for the treatment of COVID-19 - Preliminary Report. N Engl J Med, 2020; 383: 18131826.

5. BORBA MGS, et al. Effect of high vs low doses of chloroquine diphosphate as adjunctive therapy for patients hospitalized with severe acute respiratory syndrome coronavirus 2 (SARS-CoV-2) infection: a randomized clinical trial. JAMA Netw Open, 2020; 3:208857.

6. CAO YC, et al. Remdesivir for severe acute respiratory syndrome coronavirus 2 causing COVID-19: An evaluation of the evidence. Travel Med Infect Dis, 2020; 35: 101647.

7. CAO B, et al. A trial of lopinavir-ritonavir in adults hospitalized with severe Covid-19. N Engl J Med, 2020; 382: 17871799.

8. CHAN JF, et al. Genomic characterization of the 2019 novel human-pathogenic coronavirus isolated from a patient with atypical pneumonia after visiting Wuhan. Emerg Microbes Infect, 2020; 9(1): 221-236.

9. CHOY KT, et al. Remdesivir, lopinavir, emetine, and homoharringtonine inhibit SARS-CoV-2 replication in vitro. Antiviral Res, 2020; 178:104786.

10. CLINICALTRIALS.gov. A Trial of Remdesivir in Adults With Severe COVID-19, clinicalTrials.gov identifier (NCT number): NCT04257656. 2020.

11. de WIT E, et al. Prophylactic and therapeutic remdesivir (GS-5734) treatment in the rhesus macaque model of MERSCoV infection. PNAS, 2020; 117(12): 6771-6776

12. FENG W, et al. Severe acute respiratory syndrome coronavirus 2 (SARS-CoV-2): a review. Mol Cancer, 2020; 19(1): 100.

13. GHOSH AK, et al. Drug development and medicinal chemistry efforts toward SARS-Coronavirus and COVID-19 therapeutics. ChemMedChem, 2020; 15(11): 907-932.

14. GORDON CJ, et al. Remdesivir is a direct-acting antiviral that inhibits RNA-dependent RNA polymerase from severe acute respiratory syndrome coronavirus 2 with high potency. J Biol Chem, 2020; 295(20): 6785-6797.

15. HUANG C, et al. Clinical features of patients infected with 2019 novel coronavirus in Wuhan, China. Lancet, 2020; 395(10223): 497-506.

16. HUANG J, et al. Pharmacological Therapeutics Targeting RNA-Dependent RNA Polymerase, Proteinase and Spike Protein: From Mechanistic Studies to Clinical Trials for COVID-19: J Clin Med, 2020; 9(4): 1131.

17. KIM, J, et al. The First Case of 2019 Novel Coronavirus Pneumonia Imported into Korea from Wuhan, China: Implication for Infection Prevention and Control Measures. J Korean Med Sci, 2020; 35(5): 61.

18. KUJAWSKI SA, et al. First 12 patients with coronavirus disease 2019 (COVID-19) in the United States. medRxiv, 2020; 2020.03.09.20032896

19. KWONG KC el al. COVID-19, SARS and MERS: A neurological perspective. J Clin Neurosci, 2020; 77: 13-16

20. OGANDO NS, et al. SARS-coronavirus-2 replication in Vero E6 cells: replication kinetics, rapid adaptation and cytopathology. J Gen Virol. 2020; 101(9):925-940.

21. RECOVERY Collaborative Group, et al. Dexamethasone in hospitalized patients with Covid-19-preliminary report. New England Journal of Medicine, 2020; NEJMoa2021436

22. TANG D, et al. The hallmarks of COVID-19 disease. PLoS Pathog, 2020; 16(5): e1008536.

23. TAY MZ, et al. The trinity of COVID-19: immunity, inflammation and intervention. Nature Reviews Immunology, 2020; 20: 363-374.

24. TU H, et al. Current epidemiological and clinical features of COVID-19; a global perspective from China. J Infect, 2020; 81(1): 1-9.

25. U.S. Food and Drug Administration. Fact Sheet for health care providers: emergency use authorization (EUA) of Veklury (remdesivir). US Food and Drug Administration, Silver Spring, MD, 2020; https://www.fda.gov/media/143189/download

26. WANG C, et al. A novel coronavirus outbreak of global health concern. Lancet, 2020; 395(10223): 470-473

27. WANG M, et al. Remdesivir and chloroquine effectively inhibit the recently emerged novel coronavirus (2019-nCoV) in vitro. Cell Res, 2020; 30: 269-271.

28. WANG Y, et al. Remdesivir in Adults With Severe COVID-19: A Randomised, Double-Blind, Placebo-Controlled, Multicentre Trial. Lancet, 2020; 395(10236): 1569-1578.

29. World Health Organization. Coronavirus disease (COVID-19), Situation Report - 150. WHO National Authorities, 2020; Acesso: https://www.who.int/docs/default-source/coronaviruse/situation-reports/20200618-covid-19-sitrep150.pdf?sfvrsn=aa9fe9cf_4

30. WILLIAMSON BN, et al. Clinical benefit of remdesivir in rhesus macaques infected with SARS-CoV-2. Nature, 2020; 585: 273-276.

31. WRAPP D, et al. Cryo- EM structure of the 2019-nCoV spike in the prefusion conformation. Science, 2020; 367(6483): $1260-1263$. 